\title{
Binding to WGR Domain by Salidroside Activates PARP1 and Protects Hematopoietic Stem Cells from Oxidative Stress
}

\author{
Xue Li,, ${ }^{1,2}$ Ozlem Erden, Liang Li,, Qidong Ye, Andrew Wilson, and Wei Du ${ }^{1}$
}

\begin{abstract}
Aims: A component of the base excision repair pathway, poly(ADP-ribose) polymerase-1 (PARP1) functions in multiple cellular processes, including DNA repair and programmed cell death. We previously showed that Salidroside, a phenylpropanoid glycoside isolated from medicinal plants, prevented the loss of hematopoietic stem cells (HSCs) in native mice and rescued HSCs repopulating in transplanted recipients under oxidative stress. The aim of this study was to investigate the mechanism by which PARP1 activation by Salidroside maintains HSCs under oxidative stress. Results: We found that although there were no spontaneous defects in hematopoiesis in $\mathrm{Parpl}^{-/-}$mice, oxidative stress compromised the repopulating capacity of $\mathrm{Parpl}^{-/-}$HSCs in transplanted recipient mice. A biochemical study using truncated proteins lacking the defined functional domains of PARP1 showed that the tryptophan-glycine-arginine-rich (WGR) domain of PARP1 was critical for Salidroside binding and subsequent PARP1 activation under oxidative stress. Functionally, complementation of Parp1 $1^{-/-}$ HSCs with full-length PARP1 ${ }_{\mathrm{WT}}$, but not the PARP1 $1_{\mathrm{R} 591 \mathrm{~K}}$ mutant in WGR domain restored Salidroside-stimulated PARP1 activation in vitro. Mechanistically, activated PARP1 by Salidroside enhanced the repopulating capacity of the stressed HSCs by accelerating oxidative DNA damage repair. Innovations and Conclusion: Our findings reveal the action of mechanism for Salidroside in PARP1 stimulation and a novel role of PARP1 activation in maintaining HSC function under oxidative stress. Antioxid. Redox Signal. 20, 1853-1865.
\end{abstract}

\section{Introduction}

$\mathbf{R}$ EACTIVE OXYGEN SPECIES (ROS) are the chemical reactive molecules containing oxygen, which are routinely generated during a metabolic or inflammatory process (28). An imbalance between ROS production and antioxidant defense, defined as oxidative stress, can cause or amplify genotoxic stress and stimulate inflammatory responses (9). It has been considered as an important pathogenic factor in leukemia-prone bone marrow (BM) diseases by inducing a variety of responses in hematopoietic stem cells (HSCs), such as stem cell differentiation and apoptosis $(1,14,15,32)$. ROS can drive HSCs into cell division, which appears to be essential for DNA repair processes (46). It has been shown that oxidative DNA damage repair (ODDR) is less efficient in quiescent stem cells than in progenitor cells, and that ROS- induced DNA damage impairs the self-renewal capacity of human HSCs (43). Mice deficient in genes functioning in

Innovation
The present studies demonstrate the intrinsic repopulating
defect of Parp $^{-/-}$hematopoietic stem cells (HSCs) under
oxidative stress and identifies the tryptophan-glycine-arginine-
rich (WGR) domain of poly(ADP-ribose) polymerase-1
(PARP1) required for Salidroside binding and PARP1 ac-
tivation thereby preventing oxidative stress-induced pre-
mature HSC exhaustion. These findings not only provide a
molecular explanation for Salidroside-stimulated PARP1
activation in HSC maintenance under oxidative stress, but
also suggest new targets for therapeutically exploring the
pathogenic role of oxidative stress in hematologic diseases.

\footnotetext{
${ }^{1}$ Division of Experimental Hematology and Cancer Biology, Cincinnati Children's Hospital Medical Center, Cincinnati, Ohio.

${ }^{2}$ College of Pharmacology, South China Normal University, Guangzhou, China.

${ }^{3}$ Department of Hematology/Oncology, Shanghai Children's Medical Center, Shanghai, China.
} 
oxidative stress responses, including Atm, Fancc, Fancd2, FoxO, and in DNA damage repair, including Lig4, Dna-pk, $K u 80, X p d, m T R$, show elevated ROS levels and sustained DNA damage accumulation leading to premature HSC exhaustion $(2,4,5,18,19,24,26,28,31,33,34,41,47)$.

Poly(ADP-ribosyl)ation (PARylation) is a post-translational protein modification by creating poly(ADP-ribose) (PAR) covalently attached onto target proteins that mediate gene transcription, DNA damage repair, and cell death signaling $(4,17,23)$. Poly(ADP-ribose) polymerase-1 (PARP1) is the founding member of the PARP family with a highly conserved structure and six domains: three Zinc finger DNA-binding domain (DBD: Zn1, Zn2, and Zn3), the automodification domain (AD), the tryptophan-glycine-argininerich (WGR) domain, and the catalytic domain (CAT) that is composed of two subdomains - the helical subdomain (HD) and the ART subdomain $(17,23)$. It has emerged as a promising drug target for cancer therapy due to its role in maintaining genome stability (25). Although increasing evidence indicates that PARP1 is involved in oxidative DNA damage response $(3,7,26,45)$, how PARP1 functions in HSC maintenance under oxidative stress remains to be elucidated.

Salidroside, a phenylpropanoid glycoside, is the major active substance of Rhodiola rosea, which grows in dry and sandy ground and has been used traditionally and pharmacologically for a long period of time in many European countries in the 19 th century $(8,38)$. The main use was as a brain tonic, as a roborant, and to alleviate headache $(8,38)$. Recently, it has been documented in experimental animals for protective effects of oxygen, cold, radiation, and heavy physical exercise (8), suggesting that Salidroside has various pharmacological properties, including antiaging, anticancer, anti-inflammation, hepatoprotective, and antoxidative effects $(13,16,20)$.

We previously showed that Salidroside stimulated the PARP1 activity and protected HSCs from oxidative stress (26). To further understand the action of mechanism for Salidroside in PARP1 stimulation in the context of ODDR in HSCs, we constructed several truncated proteins lacking the defined functional domains of PARP1 and assessed the effect of these mutants in HSCs under oxidative stress and their binding to Salidroside. The results showed that Salidroside activated PARP1 through its binding to the WGR domain, while truncated proteins lacking the WGR domain or carrying R591K mutation in the WGR domain failed to bind and respond to Salidroside under oxidative stress. Functionally, Salidroside stimulated PARP1 activation in $\mathrm{Parpl}^{-/-} \mathrm{HSCs}$ expressing the wild-type (WT) PARP1 and prevented HSCs from $\mathrm{H}_{2} \mathrm{O}_{2}$-induced cycling and repopulating exhaustion. Taken together, we identified a specific binding domain of PARP1 required for Salidroside-stimulated PARP1 activation and a crucial role for PARP1 in maintaining HSC function under oxidative stress.

\section{Results}

Genetic dissection of Salidroside action on HSC function under oxidative stress

We previously showed that activation of PARP1 by Salidroside, a phenylpropanoid glycoside isolated from the medicinal plant $R$. rosea prevents the loss of HSCs in native mice and rescues HSCs repopulating in transplanted recipi- ents under oxidative stress (26). To provide genetic evidence that Salidroside protects HSCs from oxidative stress through stimulating the PARP1 activity, we employed Parpl-deficient mice $\left(\right.$ Parpl $\left.^{-/-}\right)$. We first determined the optimal dose of hydrogen peroxide $\left(\mathrm{H}_{2} \mathrm{O}_{2}\right)$; consistently with the previous finding (26), we found that $0.25 \mu \mathrm{mol} / \mathrm{g}$ body weight was the optimal dose that effectively induced oxidative stress, as evidenced by a dose-dependent increase in ROS (Supplementary Fig. S1A; Supplementary Data are available online at www.liebertpub.com/ars) and lipid peroxide (LPO) (Supplementary Fig. S1B). We then treated WT and Parp1 ${ }^{-1-}$ mice with or without Salidroside followed by $\mathrm{H}_{2} \mathrm{O}_{2}$ injection $(0.25 \mu \mathrm{mol} / \mathrm{g}$ body weight $)$. We found that $\mathrm{H}_{2} \mathrm{O}_{2}$ treatment led to significant expansion of $\mathrm{Lin}^{-} \mathrm{c}-\mathrm{kit}^{+} \mathrm{Sca}{ }^{+}$(LSK) cells in WT mice, which was partially limited by Salidroside (Fig. 1A). However, in Parp $^{-/-}$mice, Salidroside failed to prevent $\mathrm{H}_{2} \mathrm{O}_{2}$-induced LSK expansion. Specifically, there was a significant increase in LSK frequency in $\mathrm{H}_{2} \mathrm{O}_{2}$-treated Parp $^{-/-}$mice and Salidroside treatment did not reverse the effect (Fig. 1A). It is noteworthy that neither Salidroside nor $\mathrm{H}_{2} \mathrm{O}_{2}$ treatment altered the morphology of these primitive LSK cells (Fig. 1B). Further analysis of the LSK compartment indicated that $\mathrm{H}_{2} \mathrm{O}_{2}$ treatment caused a significant reduction of LT-HSCs (LSK-CD150 ${ }^{+} \mathrm{CD}_{4}{ }^{-}$) in WT mice and a further decrease of LT-HSCs in $\mathrm{Parpl}^{-/-}$mice (Fig. 1C). Salidroside almost completely abrogated $\mathrm{H}_{2} \mathrm{O}_{2}$-induced loss of LT-HSCs in WT mice, while this effect was absent in Parp $1^{-/-}$mice. Specifically, the LT-HSC number in $\mathrm{H}_{2} \mathrm{O}_{2-}$ injected $\mathrm{Parpl}^{-1-}$ mice in the presence of Salidroside remained significantly lower compared with WT mice (Fig. 1C). These results suggest that PARP1 plays an important role and is required for the action of Salidroside in maintaining a HSC pool under oxidative stress.

We then determined whether Salidroside could improve the repopulating ability of oxidative stressed Parpl $^{-/-}$HSCs by transplanting LSK cells from $\mathrm{H}_{2} \mathrm{O}_{2}$-treated WT C57BL/6 mice or Parp1 $1^{-/-}$mice (CD45.2 $2^{+}$) pretreated with or without Salidroside into lethally irradiated congenic recipients $\left(\mathrm{CD} 45.1^{+}\right)$. We observed a significant decrease of donorderived chimera $\left(\mathrm{CD} 45.2^{+}\right)$in the recipients injected with LSK cells from $\mathrm{H}_{2} \mathrm{O}_{2}$-treated WT mice, which was partially reversed by Salidroside at 4 months after transplantation (Fig. 1D). Although HSCs from vehicle-treated Parp $^{-1-}$ mice gave rise to comparable donor-derived chimera $(72.37 \% \pm 5.95 \%$ in the WT group and $69.93 \% \pm 5.09 \%$ in the Parpl $^{-/-}$group) in the recipients, oxidative stress compromised the repopulating capacity of Parpl $^{-/-}$HSCs $(10.83 \% \pm 5.58 \%)$ more when compared with WT HSCs $(31 \% \pm 4.11 \%)$. Salidroside failed to restore the ability of stressed Parp $^{-/-}$HSCs in reconstituting mouse hematopoiesis in the recipient mice $(11.5 \% \pm 3.84 \%)$. Mechanistically, Salidroside appeared to prevent HSCs from oxidative stress-induced cycling (Fig. 1E) rather than apoptosis (Fig. 1F), as detected by bromodeoxyuridine (BrdU)/7aminoactinomycin D (7AAD) and Annexin V/7AAD staining, respectively. These results collectively provide genetic evidence that PARP1 is required for the action of Salidroside in influencing HSC function under oxidative stress.

\section{Salidroside binds to the WGR domain of PARP1}

PARP1 has a highly conserved structural and functional organization, including an N-terminal zinc finger DBD, a 
nuclear localization signal, a central $\mathrm{AD}$, and a C-terminal catalytic domain $(4,17,23)$. We first determined whether Salidroside bound directly to PARP1. To this end, we constructed several truncated proteins lacking the defined functional domains of PARP1 (Fig. 2), and assessed their ability to bind to Salidroside. We employed microscale thermophoresis to determine the binding between Salidroside and the PARP1 derivatives. This technology probes for fluorescent changes in the hydration shell of molecules to measure protein-protein or protein-small molecule interactions with

A

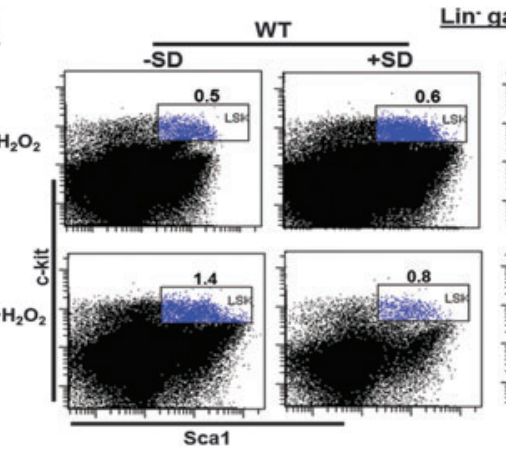

Lin- gated
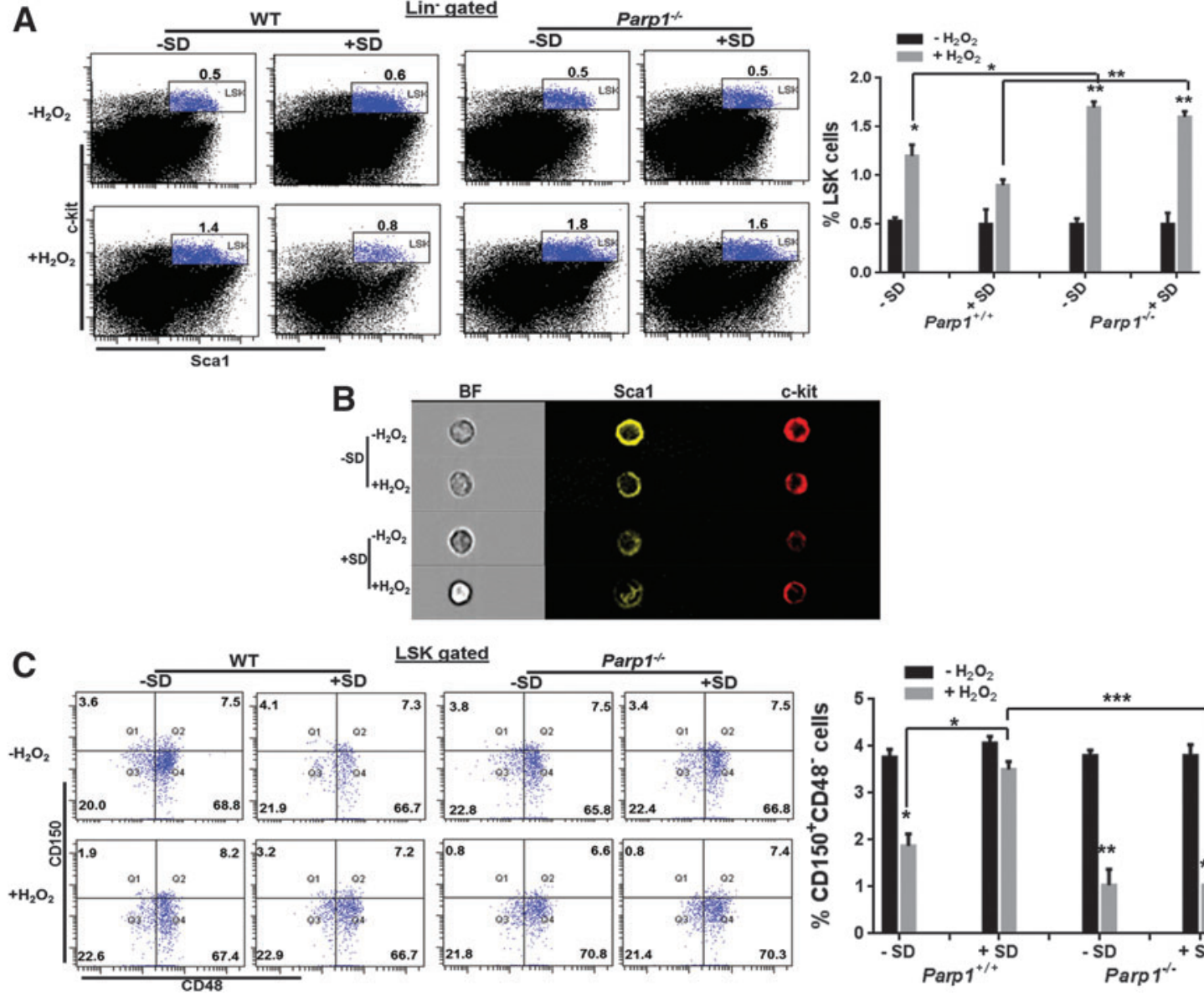

SK gated

Parp1\%
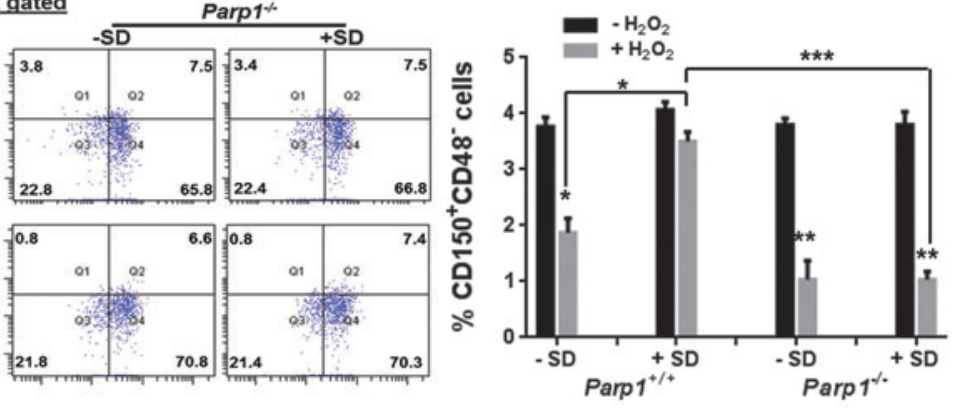

FIG. 1. Oxidative stress compromises self-renewal capacity of Parp1 ${ }^{-1-}$ HSCs. (A) Salidroside does not limit $\mathrm{H}_{2} \mathrm{O}_{2^{-}}$ induced LSK expansion in Parpl $^{-/-}$mice. BMCs from WT C57BL/6 mice or Parp1 ${ }^{-/-}$mice pretreated with or without SD ( $75 \mu \mathrm{g} / \mathrm{g}$ body weight) followed by $\mathrm{H}_{2} \mathrm{O}_{2}\left(0.25 \mu \mathrm{mol} / \mathrm{g}\right.$ body weight) injection were harvested for $\mathrm{LSK}$ ( $\mathrm{Lin}^{-} \mathrm{Sca}^{+}$ $\mathrm{c}^{-\mathrm{kit}^{+}}$) cell frequency assessment using flow cytometry. Representative flow graph (left) and quantification (right) are shown. Results are mean \pm SD of three independent experiments $\left(n=3\right.$ per group per experiment). (B) $\mathrm{H}_{2} \mathrm{O}_{2}$ and Salidroside treatment does not alter the morphology of the primitive cells. LDBMCs isolated from $\mathrm{Parpl}^{-/-}$mice pretreated with $\mathrm{H}_{2} \mathrm{O}_{2}$ in the presence or absence of Salidroside were subjected to ImageStream analysis. Cells were gated on LSK population. Representative images are shown. (C) Salidroside does not prevent $\mathrm{H}_{2} \mathrm{O}_{2}$-induced LSKCD $150^{+} \mathrm{CD} 48^{-}$cell loss in Parp1 ${ }^{-1-}$ mice. BM cells described in (A) were subjected to flow cytometry analysis for LSKCD $150^{+} \mathrm{CD} 48^{-}$frequency. Representative flow graph (left) and quantification (right) are shown. Results are mean $\pm \mathrm{SD}$ of three independent experiments $(n=3$ per group per experiment). (D) Salidroside does not enhance Parpl $^{-1-}$ HSC repopulation in recipient mice. LSK $\left(\mathrm{Lin}^{-} \mathrm{Scal}^{+}{ }^{\mathrm{c}-\mathrm{kit}^{+}}\right.$) cells from WT C57BL/6 mice or Parp1 ${ }^{-/-}$mice (CD45.2 $\left.2^{+}\right)$pretreated with or without Salidroside $\left(75 \mu \mathrm{g} / \mathrm{g}\right.$ body weight) followed by $\mathrm{H}_{2} \mathrm{O}_{2}(0.25 \mu \mathrm{mol} / \mathrm{g}$ body weight) treatment were isolated by cell sorting using FlowAria II. One thousand sorted LSK cells plus 1 million c-kitdepleted competitors (CD45.1 $1^{+}$) were injected to lethally irradiated recipients. Donor chimerism was examined at 4 months after transplantation using peripheral blood from recipients. Representative images (left) and quantifications $(r i g h t)$ are shown. Results

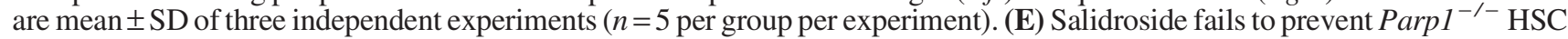
cycling in vivo. BMCs were harvested from mice described in (D) followed by 7AAD and BrdU staining to determine cycling cells in CD45.2 $2^{+}$LSK CD34- population. Representative images (left) and quantifications (right) are shown. Results are mean \pm SD of three independent experiments ( $n=3$ per group per experiment). (F) Salidroside and $\mathrm{H}_{2} \mathrm{O}_{2}$ have no effect on apoptosis of LSK CD34- cells. BMCs were harvested from mice described in (D) followed by 7AAD and Annexin V staining to determine apoptotic cells in the CD45.2 ${ }^{+}$LSK CD $34^{-}$population. Representative images (left) and quantifications (right) are shown. Results are mean $\pm \mathrm{SD}$ of three independent experiments $\left(n=3\right.$ per group per experiment). ${ }^{*} p<0.05$; $* * p<0.01$; $* * * p<0.001$. BMCs, bone marrow cells; LDBMCs, low-density bone marrow cells; BrdU, bromodeoxyuridine; 7AAD, 7 aminoactinomycin D; HSC, hematopoietic stem cell; PARP1, poly(ADP-ribose) polymerase-1; SD, Salidroside; WT, wild type. To see this illustration in color, the reader is referred to the web version of this article at www.liebertpub.com/ars 

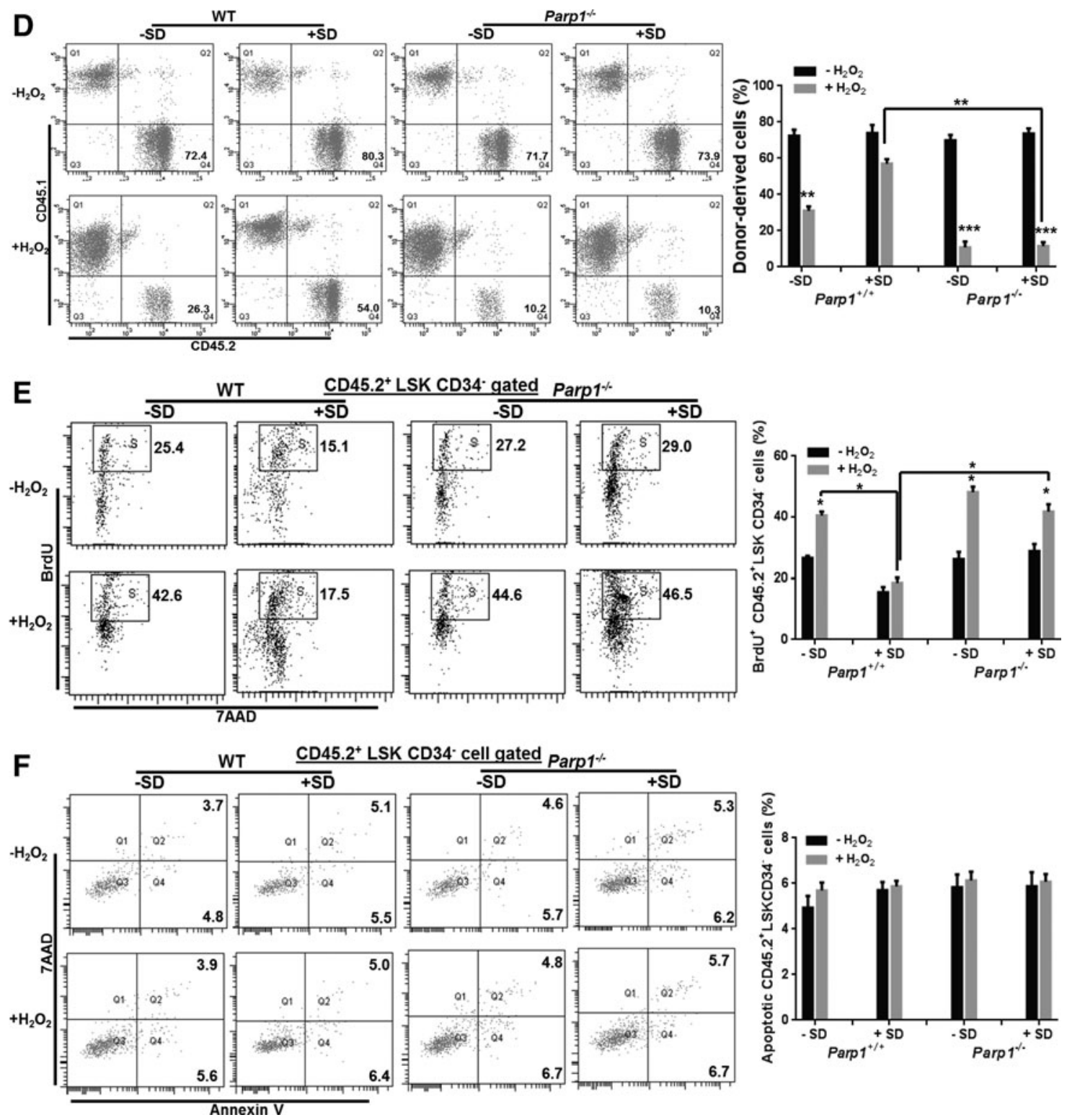

FIG. 1. (Continued)

high sensitivity in near-native conditions (1). Thermophoresis of the protein in the presence of varying concentrations of chemicals was analyzed for $30 \mathrm{~s}$. Measurements were performed at room temperature and standard deviation was calculated from three independent experiments. The results show that full-length PARP1 specifically bound Salidroside, but not 1-(2-(glucopyranosyl)-phenyl)-ethanone, a chemical with a similar structure to Salidroside (Supplementary Fig. S2), in titration assays and yielded a $\mathrm{K}_{\mathrm{d}}$ value of $\sim 84 \mathrm{n} M$ (Fig. 3A), while constructs without the WGR domain (PARP1 mutants deleted for C-terminus), including constructs 1 (PARP1 $1_{1-215}, \mathrm{Zn} 1$, and Zn2), 2 (PARP1 $1_{1 \text { ndash; } 375}, \mathrm{Zn} 1, \mathrm{Zn} 2$, and $\mathrm{Zn3}), 3$ (PARP1 $1_{1-479}$ ), and 4 (PARP1 $1_{1-525}, \mathrm{Zn} 1, \mathrm{Zn} 2, \mathrm{Zn} 3$, and BRCT) failed to bind Salidroside (Supplementary Fig. S3 and Table 1). We also found that PARP1 mutants deleted for $\mathrm{N}$-terminus, including constructs $5\left(\mathrm{PARP}_{216-1014}, \mathrm{~N}\right.$-terminal deletion of Zn1), 6 ( $\mathrm{PARP1}_{376-1014}$, $\mathrm{N}$-terminal deletion of $\mathrm{Zn} 1$ and $\mathrm{Zn} 2), 7$ (PARP1 $1_{526-1014}$, WGR-CAT domain), and 8
(PARP1 ${ }_{480-1014}$, DsDB-WGR-CAT domain, 37) had relatively comparable binding affinity to full-length PARP1 (Supplementary Fig. S3 and Table 1), suggesting that the C-terminal of PARP1 is required for Salidroside binding. To further reveal the binding between PARP1 and Salidroside, we mutated residue $\mathrm{Arg}^{591}$ in the WGR domain (Fig. 3B), which has been shown critical for the Zn1 DNA damage interface and the CAT (24). The result shows that mutagenesis of the WGR domain (R591K) disrupted the binding of PARP1 to Salidroside (Fig. 3C). Taken together, these results suggested that the WGR domain is required for Salidroside-PARP1 binding.

\section{Salidroside activates PARP1 through binding to the WGR domain in vitro}

To elucidate the action of mechanism for Salidroside in PARP1 stimulation, we isolated LSK cells from Parp1 $1^{-\prime-}$ mice and transduced them with the lentiviral vector expressing 
A
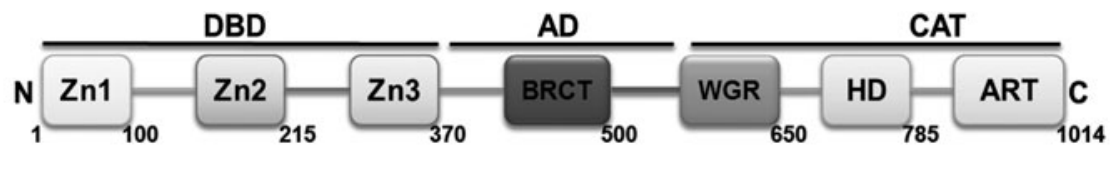

B

FIG. 2. Expression and purification of PARP1 proteins. (A) Schematic presentation of functional domains of PARP1 protein. (B) Generation of PARP1 derivatives. Sequences corresponding to the indicated PARP1 domains were cloned into the pET32a vector. (C) Expression of truncated PARP1 proteins. E. coli HMS174 (DE3) pLysS harboring different domains of PARP1 were grown in the presence $(+)$ of IPTG to induce expression of the truncated proteins. Fifty micrograms of cell lysates was analyzed by coomassie blue staining. Arrows donate the corresponding truncated proteins. (D) Western blot analysis of the truncated PARP1 proteins using the antihistidine antibody. Truncated proteins were purified by affinity chromatography on a nickel-sepharose column, followed by gel filtration on a PD-10 column. IPTG, isopropyl- $\beta$-D-1-thiogalactopyranoside.

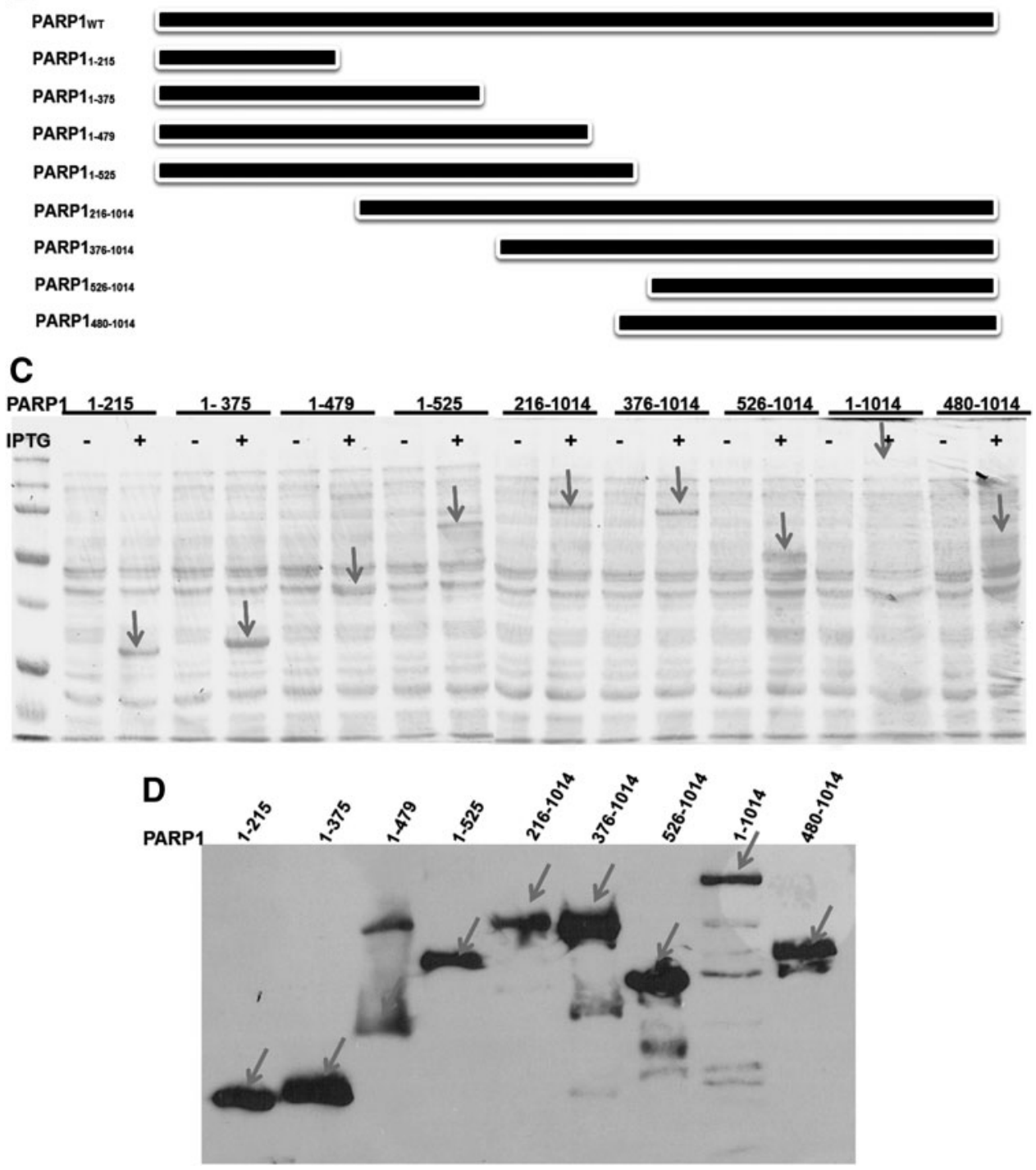

the Venus-only, Venus-PARP1 $1_{\mathrm{WT}}$, or Venus-PARP1 $1_{\mathrm{R} 591 \mathrm{~K}}$ mutant. Transduction efficiency was comparable between groups (around 90\%; Supplementary Fig. S4). We found that complementation of Parp $^{-1-}$ cells with PARP1 ${ }_{\mathrm{WT}}$ restored its activation under oxidative stress in response to Salidroside, as determined by in vitro PARP1 enzyme activity assay (Fig. 4A), which was correlated with accelerated DNA damage clearance as detected by immune blotting for $\gamma$-H2AX, a robust indicator of DNA strand breaks (Fig. 4B). Specifically, Salidroside stimulated PARP1 activity in LSK cells from Parp1 $1^{-/-}$mice complemented with PARP1 ${ }_{\mathrm{WT}}$. Furthermore, the level of $\gamma-\mathrm{H} 2 \mathrm{AX}$ decreased as early as $4 \mathrm{~h}$ after Salidroside treatment in Parpl $^{-/-}$cells complemented with PARP $1_{\mathrm{WT}}$. In contrast, Parp1 ${ }^{-/}$cells expressing the WGR mutant (PARP1 $1_{\mathrm{R} 591 \mathrm{~K}}$ ) failed to respond to Salidroside and showed sustained accumulation of DNA damage up to $12 \mathrm{~h}$ post $\mathrm{H}_{2} \mathrm{O}_{2}$ treatment (Fig. 4B). Correspondingly,
$\mathrm{PARP} 1_{\mathrm{WT}}$ but not the PARP1 $1_{\mathrm{R} 591 \mathrm{~K}}$ mutant restored in vitro the self-renewal capacity of Parp1 ${ }^{-/-}$hematopoietic stem progenitor cells as determined by the colony-forming unit (CFU) assay (Fig. 4C). Together, these results indicate that Salidroside stimulates PARP1 activation through its binding to the WGR domain of PARP1.

\section{The WGR domain is critical for PARP1 activation by Salidroside in vivo}

To substantiate the in vitro studies, we next sought to test whether the WGR domain of PARP1 was required for Salidroside-stimulated PARP1 activation in vivo. To this end, we transduced LSK cells isolated from Parp1 $^{-1-}$ mice with lentiviral vectors expressing Venus-only, Venus-PARP1 $1_{\mathrm{WT}}$, or Venus-PARP1 $1_{\mathrm{R} 591 \mathrm{~K}}$ mutant, followed by $\mathrm{H}_{2} \mathrm{O}_{2}$ treatment in the presence or absence of Salidroside. One thousand 

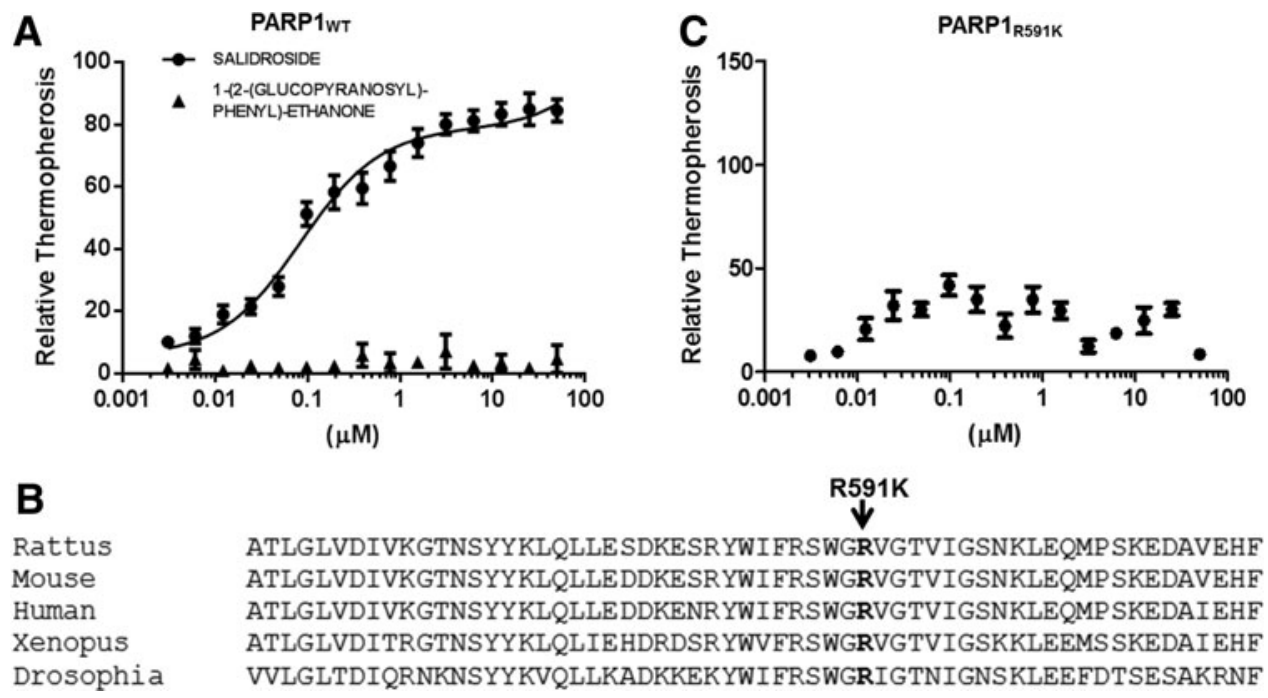

FIG. 3. Salidroside binds to WGR domain of PARP1. (A) Salidroside specifically binds to WGR domain of PARP1. Purified full-length or truncated PARP1 proteins were first labeled with Alexa-647 fluorescence dye followed by microscale thermophoresis analysis. Salidroside was titrated between 3 and 50,000 $\mathrm{n} M$ to a constant amount of labeled PARP1 proteins $(100 \mathrm{n} M)$. The reaction was performed in $50 \mathrm{~m} M$ HEPES, $50 \mathrm{mM} \mathrm{NaCl}, 0.01 \%$ Tween20, and $2 \mathrm{mM} \mathrm{MgCl} 2$. The samples were incubated at room temperature for $30 \mathrm{~min}$ before the measurements. Data were normalized to either $\Delta$ Fnorm [\%o] $\left(10^{*}\left(\right.\right.$ Fnorm(bound) - Fnorm (unbound)) ) or Fraction bound ( $\Delta$ Fnorm $[\%] /$ amplitude). The average $\mathrm{K}_{\mathrm{d}}$ values $\pm \mathrm{SD}$ were calculated from three replicates. Results are mean \pm SD of three independent experiments. (B) Mutagenesis of WGR domain. (C) WGR mutant $\left(\right.$ PARP1 $_{\text {R591K }}$ ) fails to respond to Salidroside stimulation. Purified full-length PARP1 proteins carrying the R591K mutant were used for the experiment described in (A). WGR, tryptophan-glycine-arginine-rich.

treated Venus ${ }^{+}$LSK cells were then transplanted to lethally irradiated BoyJ recipients. Four months after bone marrow transplantation (BMT), donor-derived chimera was detected by flow cytometry. The results showed that cells expressing $\mathrm{PARP} 1_{\mathrm{WT}}$, but not the empty vector or the PARP1 $1_{\mathrm{R} 591 \mathrm{~K}}$ mutant responded to Salidroside stimulation and succeeded in reconstituting recipient hematopoiesis, as determined by flow cytometry for CD45.2 $2^{+}$cell frequency in the BM of the recipient mice (Fig. 5A). We also examined the morphology of the donor-derived LSK cells after hematopoietic reconstitution by ImageStream analysis, and found no significant change in the morphological appearance of these LSK cells after reconstitution in the irradiated recipient mice (Fig. 5B).

To provide functional evidence that binding to the WGR domain of PARP1 contributes to the antioxidant effects of Salidroside in HSC maintenance, we next determined the effect

Table 1. Summary of Binding Affinity of TRUnCATED PARP1 to SALIDRoside

\begin{tabular}{lcc}
\hline Truncated protein & $K_{d}$ & Binding \\
\hline PARP1 $_{1-215}$ & - & - \\
PARP1 $_{1-375}$ & - & - \\
PARP1 $_{1-479}$ & - & - \\
PARP1 $_{1-525}$ & - & - \\
PARP1 $_{216-1014}$ & $92.62 \mathrm{n} M$ & + \\
PARP1 $_{376-1014}$ & $114.7 \mathrm{n} M$ & + \\
PARP1 $_{526-1014}$ & $256.1 \mathrm{n} M$ & + \\
PARP1 $_{480-1040}$ & $73.13 \mathrm{n} M$ & + \\
PARP1 $_{\text {WT }}$ & $84.01 \mathrm{n} M$ & + \\
PARP1 $_{\text {R591K }}$ & - & - \\
\hline
\end{tabular}

PARP1, poly(ADP-ribose) polymerase-1. of WGR-Salidroside interaction on HSC quiescence in recipients transplanted with Venus-only-, Venus-PARP1 $1_{\mathrm{WT}^{-}}$, or Venus-PARP1 $1_{\mathrm{R} 591 \mathrm{~K}}$-transduced LSK cells. We performed pyronin Y staining, an established dye to stain RNA and correlated to actively cycling cells (22). Upon $\mathrm{H}_{2} \mathrm{O}_{2}$ injection, we observed a significantly increased cell cycle progression (pyronin $^{+}$) in empty vector- or the WGR mutant $\left(\mathrm{PARP} 1_{\mathrm{R} 591 \mathrm{~K}}\right)^{-}$ transduced Parpl $^{-1-}$ HSCs, which was not attenuated by Salidroside (Fig. 5C). Consistently, the level of DNA strand break marker, $\gamma-\mathrm{H} 2 \mathrm{AX}$, remained high in the presence of Salidroside in Venus-only or Venus-PARP $1_{\mathrm{R} 591 \mathrm{~K}}$ mutanttransduced Parp1 $1^{-/-}$HSCs (Fig. 5D). In contrast, PARP1 ${ }_{\mathrm{WT}^{-}}$ complemented $\mathrm{Parpl}^{-1-}$ HSCs were prevented from $\mathrm{H}_{2} \mathrm{O}_{2}$-induced cycling by Salidroside (Fig. 5C) and showed reduced DNA damage (Fig. 5D). We also performed secondary BMT to confirm the functional relevance of binding to the WGR domain of PARP1 by Salidroside in LT-HSC maintenance. To this end, we transplanted 10 million whole bone marrow (WBM) cells from the Salidroside- and $\mathrm{H}_{2} \mathrm{O}_{2}$-treated primary recipients of Parp $^{-/-}$cells expressing Venus-only, PARP1 $1_{\mathrm{wT}}$, or the WGR mutant $\left(\mathrm{PARP}_{\mathrm{R} 591 \mathrm{~K}}\right)$, into lethally irradiated secondary WT recipients. Four months post-transplantation, we analyzed hematopoietic reconstitution derived from donor $\left(\mathrm{CD} 45.2^{+}\right)$cells. The results showed that Salidroside failed to enhance donor-derived hematopoiesis in recipients transplanted with Parpl $^{-/}$HSCs expressing the WGR mutant protein (Fig. $5 \mathrm{E})$. Thus, the effect of Salidroside on HSC maintenance under oxidative stress requires the WGR domain of PARP1.

To explore the clinical significance of Salidroside in HSC maintenance in a disease model, we employed the Fanconi anemia (FA) mouse model, in which oxidative stress has been identified as a physiologic mediator of HSC loss $(10,29,48)$. To this end, we treated $\mathrm{Fanca}^{-/-}$or $\mathrm{Fancc}^{-/-}$mice and their 

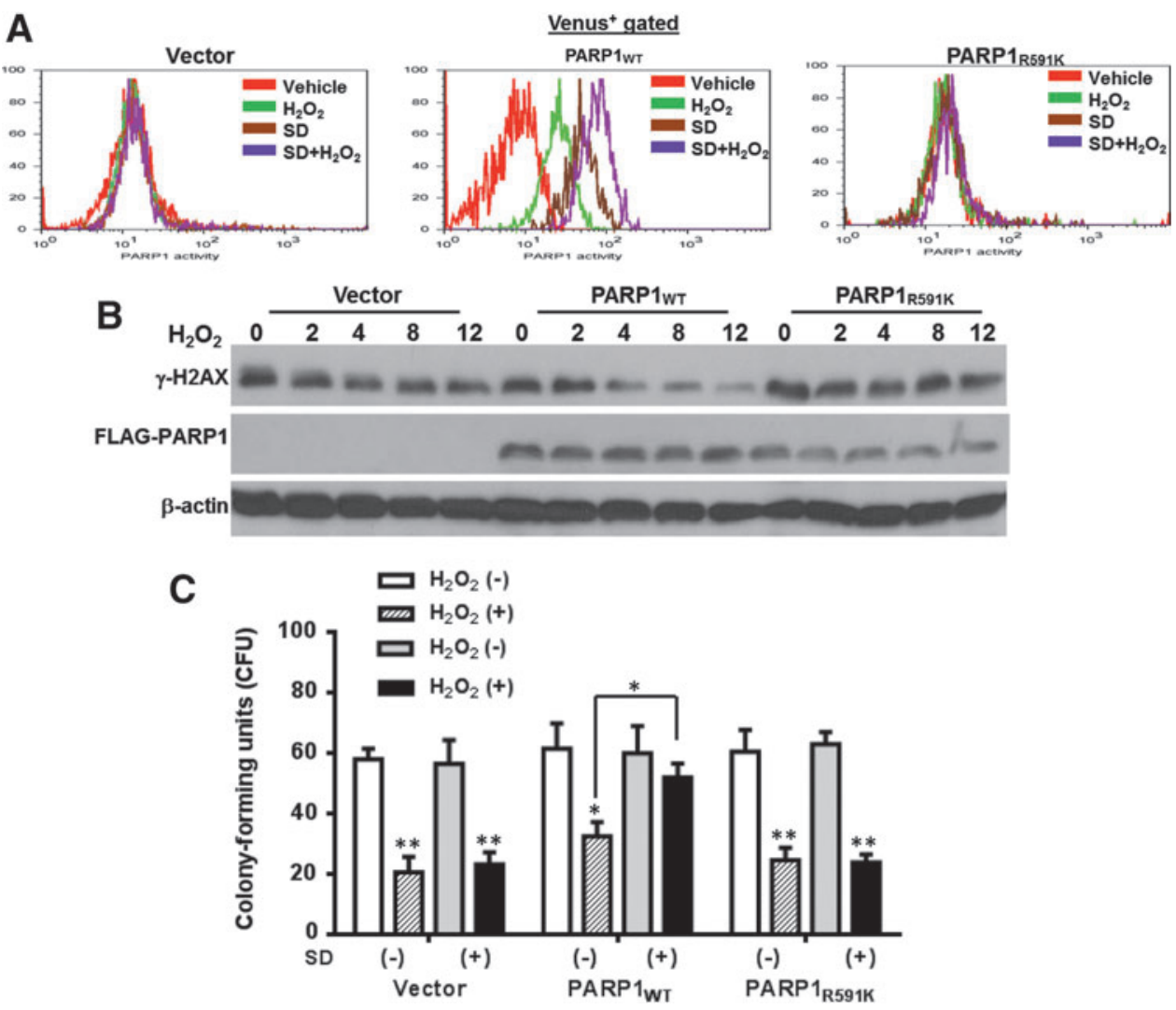

FIG. 4. Salidroside stimulates PARP1 activation through WGR domain. (A) WGR domain is required for Salidrosidestimulated PARP1 activation. LSK cells isolated from $\mathrm{Parp}^{-1-}$ mice were transduced with the lentiviral vector expressing Venusonly, Venus-PARP1 $1_{\mathrm{WT}}$, or Venus-PARP1 $1_{\mathrm{R} 591 \mathrm{~K}}$ mutant. Transduced cells were then treated with or without $\mathrm{H}_{2} \mathrm{O}_{2}$ in the presence/ absence of Salidroside followed by flow cytometry analysis for PARP1 activity. Representative flow graph gated on Venus ${ }^{+}$cells are shown. (B) Repair kinetics. Lin $^{-}$cells isolated from Parpl $^{-1-}$ mice were transduced with lentiviral vector expressing Venus-only, Venus-PARP1 $1_{\mathrm{WT}}$, or Venus-PARP1 ${ }_{\mathrm{R} 591 \mathrm{~K}}$ mutant followed by cells sorting for the Venus ${ }^{+}$population. Venus $^{+}$cells were then treated with Salidroside $(250 \mu M)$ for $2 \mathrm{~h}$, then $\mathrm{H}_{2} \mathrm{O}_{2}$ for an additional $2 \mathrm{~h}$, and released for indicated time intervals. Whole cell lysates (30,000 cells/lane) were subjected to SDS-PAGE and immunoblotted with antibodies against $\gamma$-H2AX, FLAG-M2, and $\beta$-actin. (C)

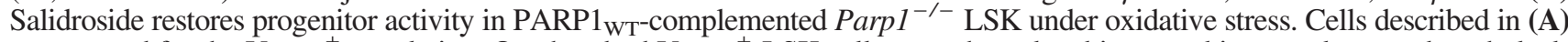
were sorted for the Venus ${ }^{+}$population. One hundred Venus ${ }^{+}$LSK cells were then plated in a cytokine-supplemented methylcellulose medium for colony formation assay. Colonies were counted on day 7. Results are mean \pm SD of three independent experiments ( $n=3$ per group per experiment). ${ }^{*} p<0.05 ; * *<<0.01 ; * * *<0.001$. SDS-PAGE, sodium dodecyl sulfate-polyacrylamide gel electrophoresis. To see this illustration in color, the reader is referred to the web version of this article at www.liebertpub.com/ars

littermates $\left(\mathrm{CD} 45.2^{+}\right)$with or without Salidroside followed by $\mathrm{H}_{2} \mathrm{O}_{2}$ injection. One thousand sorted LSK cells from the treated mice plus 1 million c-kit-depleted competitors $\left(\mathrm{CD} 45.1^{+}\right)$were then transplanted into lethally irradiated recipients $\left(\mathrm{CD} 45.1^{+}\right)$. Consistent with previous reports that FA murine HSCs have defective reconstitution after replicative stress-generating BMT $(48,49)$, we found that $\mathrm{Fanca}^{-/-}$and $\mathrm{Fancc}^{-/-}$HSCs showed poor engraftment in the recipient mice and oxidative stress further compromised their reconstituting ability (Supplementary Fig. S5). Significantly, Salidroside enhanced the ability of FA HSCs in repopulating recipient hematopoiesis (Supplementary Fig. S5). These results suggest that Salidroside may have a therapeutic value for hematologic diseases like FA, where oxidative stress plays a pathogenic role.

\section{Discussion}

The present study investigated the role of PARP1 in oxidative DNA damage responses and identified the WGR do- main as the structural element for Salidroside binding to PARP1. We propose that WGR-Salidroside binding is critical for PARP1 activation and protects quiescent HSCs from oxidative stress-induced cycling and subsequent exhaustion. We have provided several lines of evidence to support the following notions: (i) Salidroside binds to the WGR domain of PARP1 and stimulates the PARP1 activity in vitro; (ii) R591K mutation in the WGR domain of PARP1 disrupts the binding of Salidroside to PARP1; (iii) complementation of Parp1 $^{-/-}$cells with WT PARP1, but not the WGR mutant restores the Salidroside-stimulated PARP1 activation and ODDR; (iv) Parp1 $^{-/-}$HSCs expressing WT PARP1, but not the WGR mutant collaborate with Salidroside in long-term hematopoietic repopulation under oxidative stress.

We found that HSCs deficient in the Parpl gene are more sensitive to $\mathrm{H}_{2} \mathrm{O}_{2}$ treatment (Fig. 1), which leads to significant long-term HSC loss and HSC exhaustion. Recently, premature stem cell exhaustion due to accumulation of ROS or DNA damage in mice deficient in several oxidative stress 

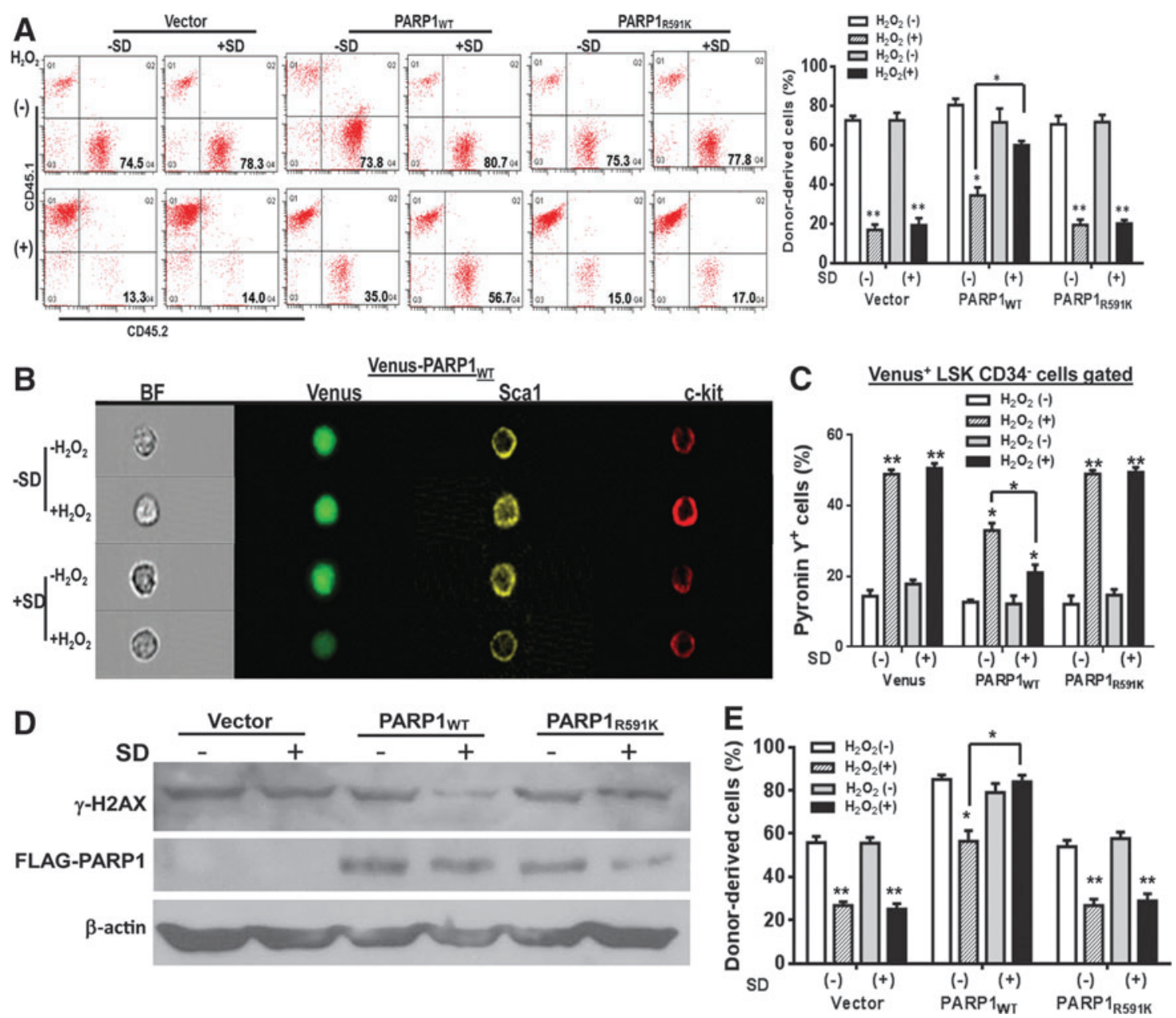

FIG. 5. WGR domain is required for PARP1 function in vivo. (A) WGR domain is essential for Salidroside-enhanced repopulating ability of stressed HSCs. LSK cells isolated from Parpl $^{-/-}$mice were transduced with the lentiviral vector expressing Venus-only, Venus-PARP1 $1_{\mathrm{WT}}$, or Venus-PARP1 $1_{\mathrm{R} 51 \mathrm{~K}}$ mutant followed by cell sorting for Venus. Venus ${ }^{+}$cells were then treated with or without $\mathrm{H}_{2} \mathrm{O}_{2}$ in the presence/absence of Salidroside followed by BMT by transplanting 1000 Venus $^{+}$cells to lethally irradiated BoyJ recipients. Four months after BMT, donor-derived chimera $\left(\mathrm{CD} 45.2^{+}\right)$was detected by flow cytometry. Representative images (upper) and quantification (lower) are shown. Results are mean \pm SD of three independent experiments ( $n=5$ per group per experiment). (B) $\mathrm{H}_{2} \mathrm{O}_{2}$ and Salidroside treatment does not alter the morphology of the cells after reconstitution. Venus ${ }^{+}$cells from recipients described in (A) were subjected to ImageStream analysis. Representative images are shown. (C) The maintenance of HSC quiescence by Salidroside requires functional PARP1. One thousand Venus ${ }^{+}$LSK cells from WT or Parpl ${ }^{-/-}$mice were injected to lethally irradiated WT recipients. Recipient mice were then subjected to Salidroside and $\mathrm{H}_{2} \mathrm{O}_{2}$ treatments. Cycling donor-derived Venus ${ }^{+}$cells were assessed by flow cytometry analysis by pyronin Y staining. Representative images (top) and quantifications (bottom) are shown.

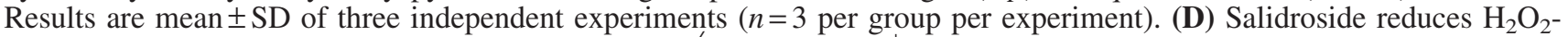
induced- $\gamma-\mathrm{H} 2 \mathrm{AX}$ in PARP1 ${ }_{\mathrm{WT}^{-}}$-complemented Parp $^{-/-}$cells. Venus ${ }^{+}$cells isolated from recipients described in $(\mathbf{C})$ were subjected to protein extraction followed by WB analysis using antibodies specific for $\gamma$-H2AX, FLAG-M2, and $\beta$-actin. (E) The enhancing effect of Salidroside on the long-term repopulation abilities of stressed HSCs requires PARP1. BMCs from primary recipients described in (B) were used for second transplantation by injecting 10 million whole BM cells to lethally irradiated WT recipients. Donor-derived cells were determined by flow cytometry analysis. Results are mean \pm SD of three independent experiments ( $n=3$ per group per experiment). ${ }^{*} p<0.5 ; * * p<0.01 ; * * * p<0.001$. BMT, bone marrow transplantation. To see this illustration in color, the reader is referred to the web version of this article at www.liebertpub.com/ars

responses, such as Atm, Fancc, Fancd2, FoxO, or DNA damage repair, such as Lig4, Dna-pk, Ku80, Xpd, mTR genes, has been reported $(28,43,46)$. We further show that the phenylpropanoid glycoside from medicinal plants, Salidroside, prevents LSK expansion and excessive stem cell cycling in WT mice, but fails to protect Parp $^{-1-}$ HSCs from oxidative stress. This finding was confirmed by BMT using Salidroside-treated Parpl $^{-/-}$LSK cells. These results pro- vide genetic evidence that the antioxidant effect of Salidroside on the function of HSCs requires PARP1.

Poly(ADP-ribose) polymerase-1 (PARP1) is an enzyme that catalyzes post-translational modifications with ADPribose polymers, which play critical roles in multiple cellular processes, including gene transcription, DNA damage detection/repair, and cell death signaling (35). The molecular architecture of PARP1 has been a subject of intensive 
investigation $(17,23,27)$. Among the structural domains, the function of WRG domain is less known. Recent study indicates that the WGR domain is a central component of the complex, interacting with $\mathrm{Zn} 1, \mathrm{Zn} 3, \mathrm{CAT}$, and DNA, forming a network of interdomain contacts that links the DNA damage interface to the CAT domain (23). Structurally, a key Zn1-WGR contact is a salt bridge formed between Asp ${ }^{45}$ of $\mathrm{Zn} 1$ and $\mathrm{Arg}^{591}$ of WGR domain. Arg ${ }^{591}$ also interacts with the HD domain of PARP1 (23). In this study, we determined the binding of Salidroside to a set of truncated PARP1 peptides by in vitro microscale thermophoretic analysis and found that Salidroside specifically bound full-length PARP1 or the truncated proteins containing the WGR domain. Furthermore, mutagenesis of R591K in the WGR domain disrupted the binding (Fig. 3 and Supplemenaty Fig. S3), suggesting that the WGR domain is required for Salidroside binding. Functionally, Salidroside stimulated PARP1 activation and ODDR in Parp1 $^{-/-}$HSCs expressing only the PARP1 protein containing a functional WGR domain under oxidative stress (Fig. 4). This stimulation also enhanced the repopulating capacity of the stressed HSCs in irradiated recipients (Fig. 5). Taken together, our results indicate that the WGR domain of PARP1 is the structural determinant for Salidroside-PARP1 binding and PARP1 activation in the context of stressed hematopoiesis.

Another interesting finding of our study is that Parp1 ${ }^{-/-}$ HSCs display increased cycling under oxidative stress, probably due to accumulation of unrepaired DNA damage. Genomic DNA integrity is a limiting factor in the maintenance of a functional HSC (28). Recent studies using mouse models deficient for homologous recombination, nonhomologous end-joining, nucleotide excision repair, and telomere maintenance pathways have shown the importance of DNA repair pathways in maintaining the HSC function (9, 11, 37, 39). Although studies have begun to connect the molecular functions of PARP1 to specific physiological and pathological outcomes $(27,35)$, the role of PARP1 in HSC maintenance remains to be elucidated. Our present results suggest that oxidative stress compromises the self-renewal capacity of Parpl $^{-/-}$HSCs (Fig. 1D), which is associated with sustained DNA damage accumulation (Fig. 4B), increased HSC cycling (Fig. 1E, C). In addition, by employing the FA mouse model, a blood disease associated with oxidative stress, our present study accentuated the therapeutic potential of Salidroside in HSC maintenance. Our findings are also consistent with recent studies that an intact DNA repair network is required for oxidative stress-induced DNA damage repair and HSC maintenance (28, 30, 34, 46). Although further studies are required to reveal the molecular mechanisms of PARP1 activation in protecting HSCs from oxidative stress-induced DNA damage, it is intriguing that Salidroside-stimulated PARP1 activity contributed to the accelerated repair of oxidative DNA damage in the stressed HSCs and the enhanced repopulating capacity in the recipients. In this context, our data lend support to the notion that DNA repair is essential for the maintenance of HSC selfrenewal capacity $(9,11,37,39)$.

\section{Materials and Methods}

Mice

129SParp1 ${ }^{\text {tmlzqw/J }}$ (The Jackson Laboratory, Bar Harbor, ME) was backcrossing with WT C57BL/6 mice for eight generations before interbreeding heterozygous Parp $^{+/-}$ mice to generate $\mathrm{Parpl}^{-/-}$mice. $\mathrm{Fanca}^{-/-}$and $\mathrm{Fancc}^{-/-}$ mice were generated by interbreeding the heterozygous $\mathrm{Fanca}^{+/-}$mice $(\mathrm{C} 57 \mathrm{BL} / 6)$ (provided by Dr. Madeleine Carreau at Laval University) (44) or $\mathrm{Fancc}^{+/-}$mice (provided by Dr. Manuel Buchwald at Hospital for Sick Children, University of Toronto) (6), respectively. All the animals, including BoyJ mice, were maintained in the animal barrier facility at the Cincinnati Children's Hospital Medical Center.

\section{Chemicals}

For in vivo experiments, mice were injected with Salidroside (75 $\mu \mathrm{g} / \mathrm{g}$ body weight; PhytoLab, Vestenbergsgreuth, Germany), or saline vehicle, intraperitoneally (i.p.) followed by $\mathrm{H}_{2} \mathrm{O}_{2}(0.25 \mu \mathrm{mol} / \mathrm{g}$ body weight; Sigma-Aldrich, St Louis, MO) (26). All experimental procedures conducted in this study were approved by the Institutional Animal Care and Use Committee of Cincinnati Children's Hospital Medical Center.

For thermophoresis analysis, Salidroside or 1-(2-(glucopyranosyl)phenyl)-ethanone (Sigma-Aldrich), which shares a similar chemical construct with Salidroside, was titrated (3$50,000 \mathrm{n} M)$ to a constant amount of labeled truncated PARP1 proteins $(100 \mathrm{n} M)$.

\section{Molecular cloning and materials}

Sequences corresponding to different PARP1 domains were cloned into the $\mathrm{pET} 32 \mathrm{a}$ vector (a gift from Dr. Masahiko Satoh at Laval University Medical Center) (12). Proteins were expressed in HMS174 (DE3) pLysS (Stratagene, Santa Clara, CA) and purified using nickel-nitrilotriacetic acid agarose gel chromatography (Qiagen, Valencia, CA). In addition to His tag, FLAG tag was also attached at the Nterminus of each construct.

For lentiviral vector construction, FLAG-tagged fulllength PARP1 cDNA was cloned into the pRRL-SIN-cPPTMNDU3-MCS-IVW (TMND-IRES-Venus) vector (a gift from Dr. Punam Malik at the Cincinnati Children's Hospital Medical Center), which is a HIV-based self-inactivating (SIN) lentiviral vector containing the central polypurine and termination tract (cPPT). The expression of PARP1 is controlled by a modified MNDU3 promoter. The vector also carries the internal ribosome entry site (IRES) followed by Venus and woodchuck hepatitis virus post-transcriptional regulatory element (WPRE).

Mutagenesis was carried out using the QuickChange Lightening Site-Directed Mutagenesis Kit (Stratagene).

\section{Microscale thermophoretic analysis}

Purified different truncated PARP1 proteins were first labeled with Alexa-647 fluorescence dye (NanoTemper, München, Germany). Salidroside or 1-(2-(glucopyranosyl)phenyl)-ethanone were titrated $(3-50,000 \mathrm{n} M)$ to a constant amount of labeled truncated PARP1 proteins $(100 \mathrm{n} M)$. The reaction was performed in $50 \mathrm{~m} M$ HEPES, $50 \mathrm{~m} M \mathrm{NaCl}$, $0.01 \%$ Tween 20 , and $2 \mathrm{mM} \mathrm{MgCl} 2$. Then, the samples were incubated in room temperature for $1 \mathrm{~h}$ before analyzing by microscale thermophoresis. A NanoTemper Monolith Instrument (NT.015; NanoTemper) was used for measuring thermophoresis. In this instrument, an infrared laser 
(IR-laser) beam couples into the path of light (i.e., fluorescence excitation and emission) with a dichroic mirror and is focused into the sample fluid through the same optical element used for fluorescence imaging. The IR-laser is absorbed by the aqueous solution in the capillary and locally heats the sample with a $1 / \mathrm{e} 2$ diameter of $25 \mu \mathrm{m}$. Up to $24 \mathrm{~mW}$ of laser power was used to heat the sample without damaging the biomolecules (42).

To analyze the thermophoresis of a sample, $4 \mu \mathrm{l}$ was transferred in a hydrophilic-treated glass capillary (NanoTemper). Thermophoresis of the protein in the presence of varying concentrations of compound was analyzed for $30 \mathrm{~s}$. Measurements were performed at room temperature and standard deviation was calculated from three independent experiments. Binding data were analyzed using Graphpad Prism to estimate $\mathrm{K}_{\mathrm{d}}$ values. Data were normalized to either $\Delta$ Fnorm $[\%]$ ] $(10 *($ Fnorm(bound) - Fnorm (unbound $)))$ or Fraction bound ( $\Delta$ Fnorm $[\%]$ /amplitude).

\section{PARP1 enzyme activity}

The PARP1 enzyme activity was detected following the established protocol (PARP1 Enzyme Activity Assay; Millipore, Billerica, MA) and the previous publications $(21,26)$ for the measurement of cellular poly(ADP-ribosyl)ation capacity. Briefly, cells $\left(2 \times 10^{5}\right.$ per data point) were centrifuged at $326 \mathrm{~g}$ for $5 \mathrm{~min}$ and resuspended in $100 \%$ ethanol and left at $-20^{\circ} \mathrm{C}$ for at least $20 \mathrm{~min}$. Cells were then permeabilized in $10 \mathrm{ml}$ of buffer A $(10 \mathrm{~m} M$ Tris- $\mathrm{HCl} \mathrm{pH} 7.8,1 \mathrm{~m} M$ ethylenediaminetetraacetic acid [EDTA], $4 \mathrm{mM} \mathrm{MgCl}_{2}$, and $30 \mathrm{~m} M$ 2-mercaptoethanol). Then, cells were centrifuged again at $815 \mathrm{~g}$ for $10 \mathrm{~min}$ and resuspended in buffer A again and transferred to a $\mathrm{V}$-shaped 96-well plate on ice for at least $5 \mathrm{~min}$. Then, $20 \mu \mathrm{l}$ of $3 \times$ reaction buffer (with or without $\mathrm{NAD}^{+}$) plus $13 \mu \mathrm{l}$ of $15 \mathrm{mM} \mathrm{NaCl}$ incorporating were added to the reaction mix followed by a $37^{\circ} \mathrm{C}$ incubation for $10 \mathrm{~min}$. Controls (cells with a reaction buffer in the absence of $\mathrm{NAD}^{+}$) were always included in all the experiments to define the background. Then, second fixation was done by adding $60 \mu \mathrm{l}$ of $4 \%$ formaldehyde/phosphate-buffered saline (PBS) for $20 \mathrm{~min}$ at room temperature. Sixty microliters of $100 \mathrm{mM}$ glycine in PBS was then added to quench the reaction. Cells were then centrifuged at $815 \mathrm{~g}$ for $10 \mathrm{~min}$ and resuspended in $100 \mu \mathrm{l}$ of primary antibody (anti-PARP1 antibody; Acris, San Diego, CA) diluted in a fluorescence-activated cell sorter (FACS) buffer (BD Biosciences, San Jose, CA) and incubated at $37^{\circ} \mathrm{C}$ for $1 \mathrm{~h}$ or overnight at $4^{\circ} \mathrm{C}$. Then, the cells were washed and resuspended in $100 \mu$ l of diluted secondary antibody (PE-conjugated goat anti-mouse; Invitrogen, Grand Island, NY) followed by a $37^{\circ} \mathrm{C}$ incubation for $30 \mathrm{~min}$ in the dark. Cells were washed and resuspended for flow cytometry analysis. Similar levels of background were detected between samples.

\section{Flow cytometry and cell cycle analysis}

The lineage marker (Lin) mixture (BD Biosciences) for $\mathrm{BM}$ cells from treated or untreated mice included the following biotinylated antibodies: CD3 $\varepsilon$ (145-2C11), CD11b (M1/70), CD45R/B220 (RA3-6B2), mouse erythroid cells Ly-76 (Ter119), and Ly6G and Ly-6C (RB6-8C5). Other conjugated antibodies (BD Biosciences, San Jose, CA) used for surface staining included CD45.1 (A20), CD45.2 (A104),
Sca1 (D7), c-kit (2B8), CD48 (HM48-1), and CD150 (9D1). Biotinylated primary antibodies were detected by incubation of antibody-coated cells with streptavidin-PerCP or fluorescein isothiocyanate (FITC) (BD Biosciences) in a two-step staining procedure. The percentage of apoptotic cells was determined by Annexin $\mathrm{V}$ and 7AAD staining (BD Biosciences) according to the manufacturer's instructions. For some of the experiments, pacific blue-conjugated CD45.2 (A104; BioLegend, San Diego CA) was used to determine donor-derived cells. For cell cycle analysis, cells were surface stained, fixed, and permeabilized in the BD Cytofix/ Cytoperm Buffer (BD Biosciences), then stained with $5 \mu \mathrm{g} /$ $\mathrm{ml}$ Hoechst 33342 and $150 \mathrm{ng} / \mathrm{ml}$ Pyronin Y (SigmaAldrich). Cells were then subjected to Flow Cytometric analysis (BD Biosciences).

\section{BrdU incorporation assay}

Subject mice were injected with BrdU $(150 \mu \mathrm{l}$ of $10 \mathrm{mg} /$ $\mathrm{ml}$ ) (40) i.p. followed by BM cells isolation $14 \mathrm{~h}$ later. BrdUincorporated cells (S phase) were analyzed with the FITC BrdU Flow Kit (BD Biosciences), following the manufacturer's instructions. Briefly, cells were surface stained, then fixed, and permeabilized by the BD Cytofix/Cytoperm Buffer. After $1 \mathrm{~h}$ of incubation with DNase at $37^{\circ} \mathrm{C}$, cells were stained with the APC-conjugated anti-BrdU monoclonal antibody. 7-AAD was added to each sample right before the flow cytometry analysis (BD Biosciences).

\section{CFU assay}

LSK cells isolated from Parp1 $^{-/-}$mice were transduced with lentivirus-expressing indicated construct. One hundred of transduced cells were seeded in duplicate and cultured in a cytokine-supplemented methylcellulose medium (MethoCult 3434; Stem Cell Technologies, Vancouver, Canada) in 35-mm gridded dishes. Colonies were counted on day 7.

\section{Bone marrow transplantation}

One thousand sorted LSK cells from $\mathrm{H}_{2} \mathrm{O}_{2}$-treated mice $\left(\mathrm{CD} 45.2^{+}\right)$pretreated with or without Salidroside, along with 1 million BM cells (depleted of ${\mathrm{c}-\mathrm{Kit}^{+}}^{+}$cells to provide shortterm hematopoiesis after irradiation using CD117 MicroBeads (Miltenyi Biotec, Auburn, CA) obtained from congenic WT mice $\left(\mathrm{CD} 45.1^{+}\right)$were injected into lethally irradiated $(11 \mathrm{~Gy})$ congenic recipients $\left(\mathrm{CD} 45.1^{+}\right)$by tail vein injection. Hematopoietic reconstitution in recipient mice by donor $\left(\mathrm{CD} 45.2^{+}\right)$cells at 8 and 16 weeks post-transplantation was determined by the CD45.1-PE and CD45.2-FITC marker staining followed by flow cytometry FACS Canto I (BD Biosciences) analysis. For second transplantation, $10 \times 10^{6}$ bone marrow cells (BMCs) from the primary transplants (16 weeks after transplantation) were injected into lethally irradiated congenic $\left(\mathrm{CD} 45.1^{+}\right)$recipients.

\section{Preparation of cell extracts, immunoblotting}

To prepare whole cell extracts, cells were washed with icecold PBS and resuspended in the ice-cold lysis buffer containing $50 \mathrm{~m} M$ Tris-HCL (pH 7.4), $0.1 \% \mathrm{NP} 40$, and $1 \mathrm{M} \mathrm{NaCl}$ supplemented with protease and phosphatase inhibitors (10 $\mu \mathrm{g} / \mathrm{ml}$ aprotinin, $25 \mu \mathrm{g} / \mathrm{ml}$ leupeptin, $10 \mu \mathrm{g} / \mathrm{ml}$ pepstatin A, $2 \mathrm{~m} M$ PMSF, $0.1 M \mathrm{NaP}_{2} \mathrm{O}_{4}, 25 \mathrm{~m} M \mathrm{NaF}$, and $2 \mathrm{~m} M$ 
sodium orthovandate) for $30 \mathrm{~min}$ on ice. Cell lysates were resolved on sodium dodecyl sulfate-polyacrylamide gel electrophoresis (SDS-PAGE), and immunoblots were analyzed with antibodies for the active form of $\gamma-\mathrm{H} 2 \mathrm{AX}$ (Millipore, Billerica, MA), FLAG-M2, or $\beta$-actin (SigmaAldrich). Each lane contains protein from 30,000 cells. Signals were visualized by incubation with anti-mouse or anti-rabbit secondary antibodies followed by ECL chemiluminescence (Amersham Biosciences, Piscataway, NJ).

\section{Measurement of oxidative stress}

Surface marker-stained low-density bone marrow cells (LDBMCs) were incubated with CM- $\mathrm{H}_{2}$ DCFDA (Molecular Probes, Eugene, OR; Invitrogen) in the dark for $15 \mathrm{~min}$ at $37^{\circ} \mathrm{C}$. After washing, the cells were analyzed by flow cytometry using a FACSCanto (BD Biosciences). Data were analyzed using the FlowJo program (Tree Star, Ashland, OR).

Lipid peroxides were directly quantified using an ELISA assay that measures conversion of ferrous ions to ferric ions with the Lipid hydroperoxidase Assay Kit (Cayman, Ann Arbor, MI). Briefly, WBMCs isolated from $\mathrm{H}_{2} \mathrm{O}_{2}$-treated mice were resuspended with Extract $\mathrm{R}$ (Lipid hydroperoxidase Assay Kit) saturated methanol. Then, $1 \mathrm{ml}$ of cold chloroform was added to the test tube followed by centrifugation at $1500 \mathrm{~g}$ for $5 \mathrm{~min}$ at $0^{\circ}$. Then, the bottom chloroform layer was collected by a syringe needle along the side of the test tube and transferred to another tube. The chromogen was prepared by mixing equal volumes of FTS Reagent 1 and FTS Reagent 2 in a test tube and vortex. Then, $50 \mu$ l of the freshly prepared chromogen was added to each assay tube and mixed well by vortexing followed by room temperature incubation for $5 \mathrm{~min}$. Then, $300 \mu \mathrm{l}$ of samples from each tube were transferred into the 96-well plate for the absorbance reading at $500 \mathrm{~nm}$ using SpectraMax Absorbance Microplate Reader (Molecular Devices, Sunnyvale, CA).

\section{ImageStream analysis}

LDBMCs isolated from $\mathrm{Parpl}^{-/-}$mice or donor-derived Venus ${ }^{+}$cells from recipient mice, pretreated with or without $\mathrm{H}_{2} \mathrm{O}_{2}$ in the presence or absence of Salidroside, were stained for surface markers using antibodies against lineage markers (the lineage marker [Lin] mixture; BD Biosciences), Sca1, and c-kit (BD Biosciences) followed by ImageStream analysis (Amnis Corporation, Seattle, WA). The data were analyzed by IDEADS software (Amnis Corporation).

\section{Statistical analysis}

Paired or unpaired Student's $t$-test was used for two-group comparison and one-way ANOVA for more than two-group comparison. Values of $p$ less than 0.05 were considered statistically significant. Results are presented as mean \pm SD. * Indicates $p<0.05 ; * *$ indicates $p<0.01 ; * * *$ indicates $p<0.001$.

\section{Acknowledgments}

We thank Dr. Madeleine Carreau (Laval University) for the $\mathrm{Fanca}^{+/-}$mice, Dr. Manuel Buchwald (Hospital for Sick Children, University of Toronto) for the Fancc ${ }^{-1-}$ mice, Dr. Punam Malik (Cincinnati Children's Hospital Medical Center) for the lentiviral vector, Dr. Satoh Masahiko (Laval
University Medical Center) for the pET32a-PARP1 plasmid, the Vector Core of the Cincinnati Children's Research Foundation (Cincinnati Children's Hospital Medical Center) for the preparation of lentivirus, and the Comprehensive Mouse and Cancer Core of the Cincinnati Children's Research Foundation (Cincinnati Children's Hospital Medical Center) for bone marrow transplantation service. This work was supported by the National Natural Science Foundation of China (81370608), the Guangdong Natural Science Foundation (S2013010013350), the Visiting Scholarships from South China Normal University, and the Shanghai Children's Medical center. WD is supported by a NIH T32 grant.

\section{Authors' Contributions}

$\mathrm{XL}$, designed research, performed research, analyzed data, and wrote the article; OE, LL, QY, AW, performed research; WD, designed research, analyzed data, and wrote the article.

\section{Author Disclosure Statement}

The authors declare no conflicts of interest.

\section{References}

1. Attar EC and Scadden DT. Regulation of hematopoietic stem cell growth. Leukemia 18: 1760-1768, 2004.

2. Beauséjour C. Bone marrow-derived cells: the influence of aging and cellular senescence. Handb Exp Pharmacol 180: 67-88, 2007.

3. Bertram $\mathrm{C}$ and Hass R. Cellular responses to reactive oxygen species-induced DNA damage and aging. Biol Chem 389: 211-220, 2008.

4. Bürkle A and Virág L. Poly(ADP-ribose): PARadigms and PARadoxes. Mol Aspects Med 34: 1046-1065, 2013.

5. Cairney CJ, Sanguinetti G, Ranghini E, Chantry AD, Nostro MC, Bhattacharyya A, Svendsen CN, Keith WN, and Bellantuono I. A systems biology approach to Down syndrome: identification of Notch/Wnt dysregulation in a model of stem cells aging. Biochim Biophys Acta 92: 353363, 2009.

6. Chen M, Tomkins DJ, Auerbach W, McKerlie C, Youssoufian H, Liu L, Gan O, Carreau M, Auerbach A, Groves T, Guidos CJ, Freedman MH, Cross J, Percy DH, Dick JE, Joyner AL, and Buchwald M. Inactivation of Fac in mice produces inducible chromosomal instability and reduced fertility reminiscent of Fanconi anaemia. Nat Genet 112: 448-451, 1996.

7. Chevanne M, Calia C, Zampieri M, Cecchinelli B, Caldini R, Monti D, Bucci L, Franceschi C, and Caiafa P. Oxidative DNA damage repair and parp 1 and parp 2 expression in Epstein-Barr virus-immortalized B lymphocyte cells from young subjects, old subjects, and centenarians. Rejuvenation Res 10: 191-204, 2007.

8. Darbinyan V, Kteyan A, Panossian A, Gabrielian E, Wikman G, and Wagner H. Rhodiola rosea in stress induced fatigue-A double-blind crossover study of a standardized extract SHA-5 with a repeated low-dose regimen on the mental performance of healthy physicians during night duty. Phytomedicine 7: 365-371, 2000.

9. Du W, Adam Z, Rani R, Zhang X, and Pang Q. Oxidative stress in Fanconi anemia hematopoiesis and disease progression. Antioxid Redox Signal 10: 1909-1921, 2008.

10. Du W, Erden O, and Pang Q. TNF- $\alpha$ signaling in Fanconi anemia. Blood Cells Mol Dis 42: 2-11, 2013. 
11. Goodarzi AA, Jeggo P, and Lobrich M. The influence of heterochromatin on DNA double strand break repair: Getting the strong, silent type to relax. DNA Repair (Amst) 9: 1273-1282, 2010.

12. Huambachano O, Herrera F, Rancourt A, and Satoh MS. Double-stranded DNA binding domain of poly(ADPribose) polymerase-1 and molecular insight into the regulation of its activity. J Biol Chem 286: 7149-7160, 2011.

13. Iaremii IN and Grigor'eva NF. Hepatoprotective properties of liquid extract of Rhodiola rosea. Eksp Klin Farmakol 65: 57-59, 2002.

14. Ito K, Hirao A, Arai F, Matsuoka S, Takubo K, Hamaguchi I, Nomiyama K, Hosokawa K, Sakurada K, Nakagata N, Ikeda Y, Mak TW, and Suda T. Regulation of oxidative stress by ATM is required for self-renewal of haematopoietic stem cells. Nature 431: 997-1002, 2004.

15. Ito K, Hirao A, Arai F, Takubo K, Matsuoka S, Miyamoto K, Ohmura M, Naka K, Hosokawa K, Ikeda Y, and Suda T. Reactive oxygen species act through p38 MAPK to limit the lifespan of hematopoietic stem cells. Nat Med 12: 446451, 2006.

16. Kanupriya Prasad D, Sai Ram M, Kumar R, Sawhney RC, Sharma SK, Ilavazhagan G, Kumar D, and Banerjee PK. Cytoprotective and antioxidant activity of Rhodiola imbricata against tert-butyl hydroperoxide induced oxidative injury in U-937 human macrophages. Mol Cell Biochem 275: 1-6, 2005.

17. Kim MY, Zhang T, and Kraus WL. Poly(ADP-ribosyl)ation by PARP-1: 'PAR-laying' NAD + into a nuclear signal. Genes Dev 19: 1951-1967, 2005.

18. Koizumi T, Negishi M, Nakamura S, Oguro H, Satoh K, Ichinose M, and Iwama A. Depletion of Dnmt1-associated protein 1 triggers DNA damage and compromises the proliferative capacity of hematopoietic stem cells. Int $J$ Hematol 91: 611-619, 2010.

19. Kryston TB, Georgiev AB, Pissis P, and Georgakilas AG. Role of oxidative stress and DNA damage in human carcinogenesis. Mutat Res 711: 193-201, 2011.

20. Kucinskaite A, Briedis V, and Savickas A. Experimental analysis of therapeutic properties of Rhodiola rosea $\mathrm{L}$. and its possible application in medicine. Medicina (Kaunas) 40: 614-619, 2004.

21. Kunzmann A, Dedoussis G, Jajte J, Malavolta M, Mocchegiani E, and Bürkle A. Effect of zinc on cellular poly(ADP-ribosyl)ation capacity. Exp Gerontol 43: 409414, 2008.

22. Lacorazza HD, Yamada T, Liu Y, Miyata Y, Sivina M, Nunes $\mathrm{J}$, and Nimer SD. The transcription factor MEF/ ELF4 regulates the quiescence of primitive hematopoietic cells. Cancer Cell 9: 175-187, 2006.

23. Langelier MF, Planck JL, Roy S, and Pascal JM. Structural basis for DNA damage-dependent poly(ADP-ribosyl)ation by human PARP-1. Science 336: 728-732, 2012.

24. Lansdorp PM. Role of telomerase in hematopoietic stem cells. Ann NY Acad Sci 1044: 220-227, 2005.

25. Leonetti C, Biroccio A, Graziani G, and Tentori L. Targeted therapy for brain tumours: role of PARP inhibitors. Curr Cancer Drug Targets 12: 218-236, 2012.

26. Li X, Sipple J, Pang Q, and Du W. Salidroside stimulates DNA repair enzyme Parp-1 activity in mouse HSC maintenance. Blood 119: 4162-4173, 2012.

27. Luo $X$ and Kraus WL. On PAR with PARP: cellular stress signaling through poly(ADP-ribose) and PARP-1. Genes Dev 26: 417-432, 2012.
28. Naka $\mathrm{K}$ and Hirao A. Maintenance of genomic integrity in hematopoietic stem cells. Int J Hematol 93: 434-439, 2011.

29. Pagano G, Talamanca AA, Castello G, Pallardó FV, Zatterale A, and Degan P. Oxidative stress in Fanconi anaemia: from cells and molecules towards prospects in clinical management. Biol Chem 393: 11-21, 2012.

30. Pang Q. HSCs: stressing out over ROS. Blood 118: 29322934, 2012.

31. Parmar K, Kim J, Sykes SM, Shimamura A, Stuckert P, Zhu K, Hamilton A, Deloach MK, Kutok JL, Akashi K, Gilliland DG, and D'andrea A. Hematopoietic stem cell defects in mice with deficiency of Fancd2 or Usp1. Stem Cells 28: 1186-1195, 2010.

32. Passegué E, Wagers AJ, Giuriato S, Anderson WC, and Weissman IL. Global analysis of proliferation and cell cycle gene expression in the regulation of hematopoietic stem and progenitor cell fates. J Exp Med 202: 599-611, 2005.

33. Qing Y, Lin Y, and Gerson SL. An intrinsic BM hematopoietic niche occupancy defect of HSC in scid mice facilitates exogenous HSC engraftment. Blood 119: 1768-1771, 2012.

34. Rossi DJ, Seita J, Czechowicz A, Bhattacharya D, Bryder D, and Weissman IL. Deficiencies in DNA damage repair limit the function of haematopoietic stem cells with age. Nature 447: 725-729, 2007.

35. Rusyn I, Asakura S, Pachkowski B, Bradford BU, Denissenko MF, Peters JM, Holland SM, Reddy JK, Cunningham ML, and Swenberg JA. Expression of base excision DNA repair genes is a sensitive biomarker for in vivo detection of chemical-induced chronic oxidative stress: identification of the molecular source of radicals responsible for DNA damage by peroxisome proliferators. Cancer Res 64: 1050-1057, 2004.

36. Seita $\mathbf{J}$ and Weissman IL. Hematopoietic stem cell: selfrenewal versus differentiation. Wiley Interdiscip Rev Syst Biol Med 2: 640-653, 2010.

37. Shuck SC, Short EA, and Turchi JJ. Eukaryotic nucleotide excision repair: from understanding mechanisms to influencing biology. Cell Res 18: 64-72, 2008.

38. Spasov AA, Wikman GK, Mandrikov VB, Mironova IA, and Neumoin VV. A double-blind placebo-controlled pilot study of the stimulating effect of Rhodiola rosea SHR-5 extract on the fatigue of students caused by stress during an examination period with a repeated low-dose regimen. Phytomedicine 7: 85-89, 2000.

39. Svilar D, Goellner EM, Almeida KH, and Sobol RW. Base excision repair and lesion-dependent subpathways for repair of oxidative DNA damage. Antioxid Redox Signal 14: 2491-2507, 2011.

40. van der Wath RC, Wilson A, Laurenti E, Trumpp A, and Liò P. Estimating dormant and active hematopoietic stem cell kinetics through extensive modeling of bromodeoxyuridine label-retaining cell dynamics. PLoS One 4: e6972, 2009.

41. Warren LA and Rossi DJ. Stem cells and aging in the hematopoietic system. Mech Ageing Dev 130: 46-53, 2009.

42. Wienken CJ, Baaske P, Rothbauer U, Braun D, and Duhr S. Protein-binding assays in biological liquids using microscale thermophoresis. Nat Commun 1: 100, 2010.

43. Wilson A, Laurenti E, Oser G, van der Wath RC, BlancoBose W, Jaworski M, Offner S, Dunant CF, Eshkind L, 
Bockamp E, Lió P, Macdonald HR, and Trumpp A. Hematopoietic stem cells reversibly switch from dormancy to self-renewal during homeostasis and repair. Cell 135: 1118-1129, 2008.

44. Wong JC, Alon N, Mckerlie C, Huang JR, Meyn MS, and Buchwald M. Targeted disruption of exons 1 to 6 of the Fanconi Anemia group A gene leads to growth retardation, strain-specific microphthalmia, meiotic defects and primordial germ cell hypoplasia. Hum Mol Genet 12: 20632076, 2003.

45. Wyrsch P, Blenn C, Bader J, and Althaus FR. Cell death and autophagy under oxidative stress: roles of poly(ADPRibose) polymerases and $\mathrm{Ca}(2+)$. Mol Cell Biol 32: 35413553, 2012.

46. Yahata T, Takanashi T, Muguruma Y, Ibrahim AA, Matsuzawa H, Uno T, Sheng Y, Onizuka M, Ito M, Kato S, and Ando K. Accumulation of oxidative DNA damage restricts the self-renewal capacity of human hematopoietic stem cells. Blood 118: 2941-2950, 2011.

47. Zhang S, Yajima H, Huynh H, Zheng J, Callen E, Chen HT, Wong N, Bunting S, Lin YF, Li M, Lee KJ, Story M, Gapud E, Sleckman BP, Nussenzweig A, Zhang CC, Chen DJ, and Chen BP. Congenital bone marrow failure in DNAPKcs mutant mice associated with deficiencies in DNA repair. J Cell Biol 193: 295-305, 2011.

48. Zhang X, Sejas DP, Qiu Y, Williams DA, and Pang Q. Inflammatory ROS promote and cooperate with the Fanconi anemia mutation for hematopoietic senescence. J Cell Sci 120(Pt 9): 1572-1583, 2007.

49. Zhang X, Shang X, Guo F, Murphy K, Kirby M, Kelly P, Reeves L, Smith FO, Williams DA, Zheng Y, and Pang Q. Defective homing is associated with altered Cdc42 activity in cells from patients with Fanconi anemia group A. Blood 112: 1683-1686, 2008.

Address correspondence to: Dr. Wei Du

Division of Experimental Hematology and Cancer Biology Cincinnati Children's Hospital Medical Center 3333 Burnet Ave. Cincinnati, $\mathrm{OH} 45229$

E-mail: wei.du@cchmc.org
Date of first submission to ARS Central, August 22, 2013; date of final revised submission, November 12, 2013; date of acceptance, December 2, 2013.

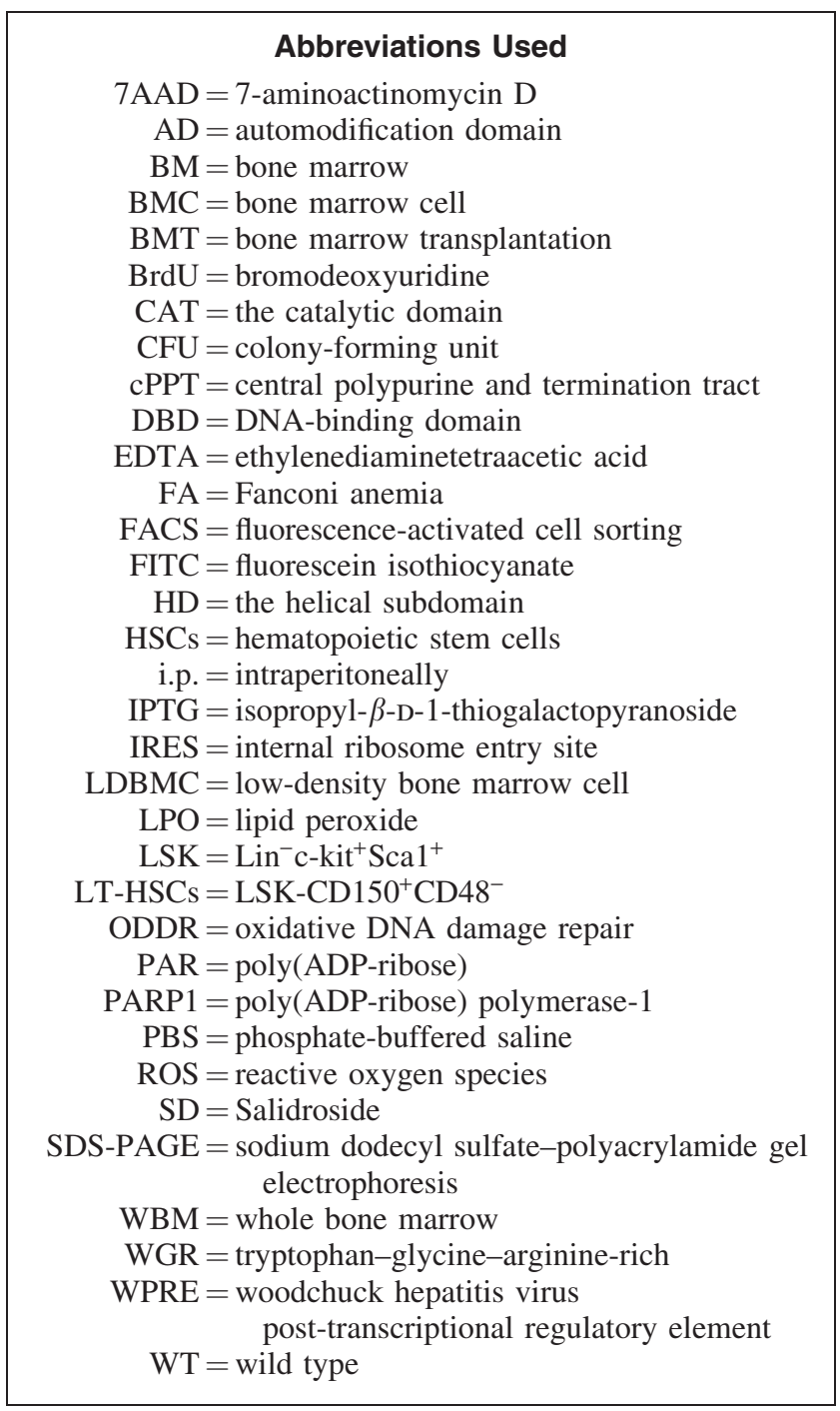

